\title{
Seismic Study of Building with Roof Top Telecommunication Towers
}

\author{
Syed Ehtesham Ali*, Izeelden Hassan,Randy A Garcia** \\ *(Structural Design Engineer at Consulting Design Engineering Tower Specialist Division, Riyadh-KSA) \\ ** (Managing Director Consulting Design Engineering Tower Specialist Division, Riyadh-KSA)
}

\begin{abstract}
Due to the boom in the telecommunication business, number of buildings carrying a roof top tower has been increased rapidly. Most of the building were not originally designed to carry a roof top tower, but later converted to carry roof top towers due to the changed requirements. In the present work an attempt has been made to study the behavior of buildings with roof top tower in the event of an Earth Quake using STAAD pro. A typical commercial building is considered for the analysis. Four towers with height $9 \mathrm{~m}, 15 \mathrm{~m}, 21 \mathrm{~m}$, and $27 \mathrm{~m}$ is considered for the study. The building is analyzed by keeping these towers at four different locations at roof top to identify the most suitable location of the tower. A comparative seismic study between buildings with and without roof top towers is done. Study is carried out to identify the most vulnerable structural members and the relative location of such members in comparison with the tower location. The difference in the forces exerted on the structural members of the building when the tower mass is lumped roof top level and at tower joint is studied in order to find out whether lumping of the tower mass at the roof top will provide satisfactory design or not.
\end{abstract}

Keywords: Multi-storey Commercial building, RCstructure, seismic analysis, Staad-Pro.

\section{INTRODUCTION}

The Indian telecom service business is the fastest growing one in the world, with over seven million mobile subscribers being added every month. This expanding base possesses challenges to mobile operators in terms of augmenting and upgrading infrastructure to maintain to quality of services. A rapidly increasing subscriber base and a more stringent spectrum allocating regime may create a higher requirement of tower sites for operators to accommodate more subscribers. Hence it became a costly and tedious task to identify sufficient land for construction of towers.

This led to the extensive use of the roof top of multistoried buildings for installing communication towers. However many of these buildings were not designed to take care of tower load, particularly under earthquake conditions. Theuse of shearwall structure has gained popularity in high rise building structure, especially in the construction of service apartment or office/commercial tower. It has been proven that this

\section{SELECTION OF BUILDING}

The floor area, the number of floors and the shape of the building on which the roof top tower is installed varies from building to building. Based on the survey of the buildings where roof top towers were installed, it has been found that most of the towers are installed on commercial buildings and their structural dimensions vary within arrange. Hence a typical commercial building frame with along span and shorts pan floor structure has been considered for the analysis. Figure1, 2, 3 shows the graphical representation of the building

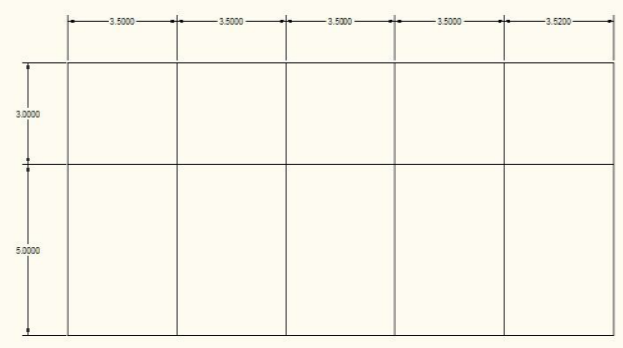

Fig1- Plan

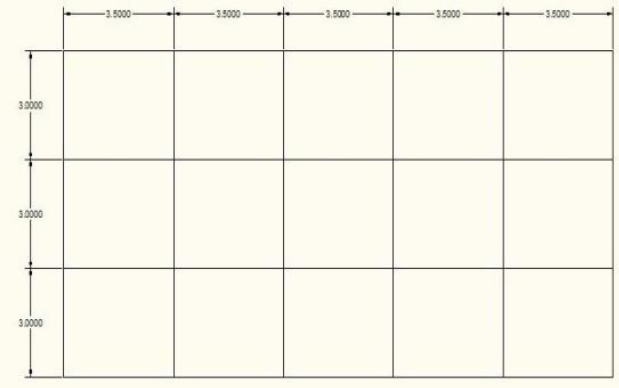




\begin{tabular}{|l|l|l|}
\hline SI.NO. & PARTICULARS & SIZE \\
\hline 1 & Number offloors & 3 \\
\hline 2 & Number ofbays & 5 \\
\hline 3 & Column grid size & $\begin{array}{l}3 \times 5 \mathrm{mand} \\
3.5 \times 3.5 \mathrm{~m}\end{array}$ \\
\hline 4 & Short beam size & $350 \times 220 \mathrm{~mm}$ \\
\hline 5 & Longbeam size & $500 \times 220$ \\
\hline 6 & Column size & $450 \times 300$ \\
\hline 7 & Slab thickness & I00 $\mathrm{mm}$ \\
\hline 8 & Wall thickness & $220 \mathrm{~mm}$ \\
\hline
\end{tabular}

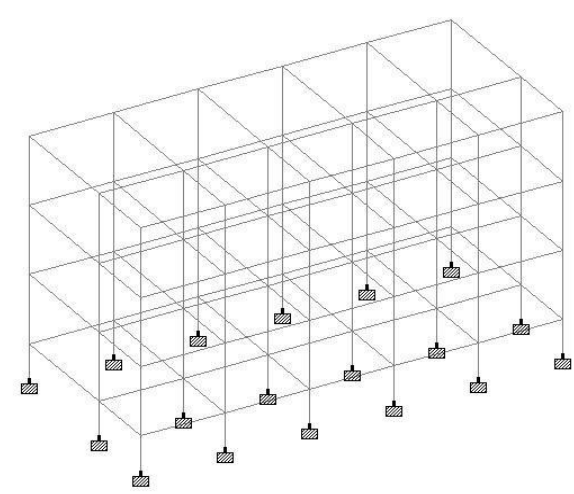

Fig3- Model

\section{TYPE OF TOWER}

In general, height of roof top tower ranges from $9 \mathrm{~m}$ to $30 \mathrm{~m}$. In order to have a wide range, four towers with heights $9 \mathrm{~m}, 15 \mathrm{~m}, 21 \mathrm{~m}$ and $27 \mathrm{~m}$ are considered for analysis. These towers are four legged steel lattice towers with cross bracings. Typical configuration of towers considered for present study is shown in figure 4, 5, 6 and 7.

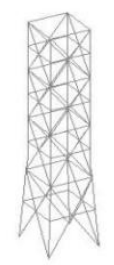

\section{Fig4-9mTower}

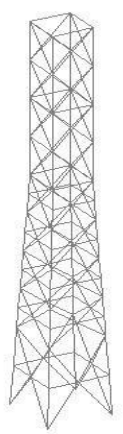

Fig5-15mTower

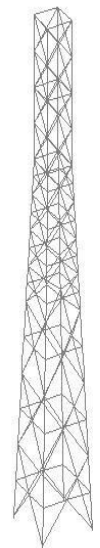

Fig6-21mTower

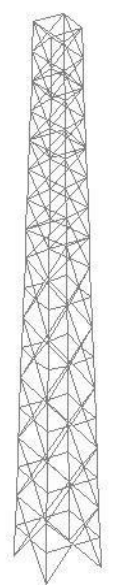

Fig7-27mTower

\section{TOWER LOCATION}

The location of tower on roof top is generally decided based on utility of remaining space. However this may lead to unfavorable conditions with respect to the structural behavior. So it has been decided to consider four locations for tower. These locations are represented as follows.

LSED-LongSpanEndDay, LSMD-LongSpanMiddleDay SSMD-ShortSpanMiddleDay, SSED-ShortSpanEndDay

Figure 8 represents the tower location

Fig 8

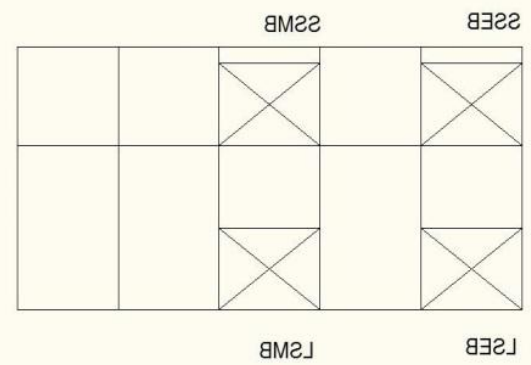




\section{TOWER LOAD}

For these analyses is of buildings with towers on roof top, bureau of Indian standards recommends to lump the mass of towers on roof top. However it is not clear whether this approach will be giving the correct assessment on the building behavior for tall towers. So it has been proposed to carry out seismic analysis of the building in two ways.

1. By lumping the tower mass at roof level

2. By considering the full tower

\section{LOADS AND LOAD COMBINATION}

Different possible loads are considered for the analysis and are computed as equivalent staticload. Different combination so floadings were used to represent maximum hogging, sagging, torsionat key sections. Loads that are considered are

\subsection{Gravity Load}

Gravity loads include dead loads and live loads. The dead loads include the permanent loads of the structure and equipment and other fixtures that ar enot likely to vary during the service life of the structure. Live loads include the variable loads due to occupants and appliances.

\subsection{Wind Load And Seismic Load}

Wind load and seismic load calculation is done as per provisions given in Indian Standard Specification (IS: 875 (Part 3) -1987 (Reaffirmed 2003), IS1893 (Part 1): 2002)

Wind load is calculated by the basic wind speed of the area and is modified to include geometric, topographic and functional parameters.

For Seismic load calculation, the building is considered to be located in zone three of the four zones in India. Vertical distribution of bases hearat different floor level is worked out for both building and tower.

\section{ANALYSIS AND DESIGN}

Analysis and design is done by using software STAAD Pro.
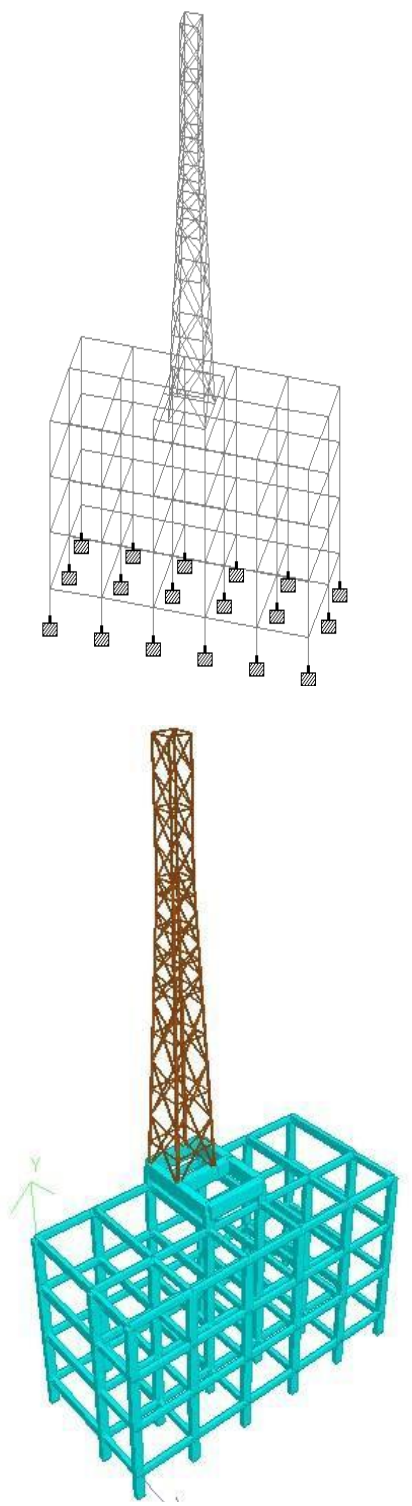

VIII. CONCLUSION

- Installing of a tower at roof top makes a building vulnerable to earthquake, as it calls for additional requirement of steel in both columns and beams.

- There is a reduction in the total steel requirement in both columns and beams, if tower is placed in the short span of the building.

- For tall towers, lumping of the tower mass at roof level of the building, underestimates the force and moment.

\section{REFERENCES}

[1]. Rola Assi and Ghyslaine McClure, 'A simplified method for seismic analysis of rooftop telecommunication towers ', Canadian journal of Civil Engineering ,Vol 34 pages 1352 to 1363 (2007) 
[2]. IS 1893(part1):2002, 'Criteria for Earthquake Resistant Design of Structures , part1,general provisions and buildings , fifth revision', New Delhi(2002)

[3]. Wang Yiqun and $\mathrm{A} \mathrm{N}$ Guotion , 'Earthquake Analysis for the system of RC buildings with steel towers', Transactions of Tianjin University, ISSN 1006-4982 pp376-380,Vol.11 No. 5 Oct. 2005

[4]. Wilson E L. Three Dimensional Static and Dynamic Analysis of Structures [M]. 3rd ed. CSI, Computer and Structures Inc, Berkeley, California, 2002

[5]. McClure, G., Lapointe, M., and Khedr, M.A. 2000. Seismic behavior of steel lattice telecommunication towers. In Behaviour of Steel Structures in Seismic Areas: STESSA 2000: Proceedings of the 3rd International Conference, Montreal, Que. Edited by F.M. Mazzolani and R. Tremblay. A.A. Balkema, Rotterdam. pp. 335-337. 